\title{
Counterconditioned fear responses exhibit greater renewal than extinguished fear responses
}

\author{
Nathan M. Holmes, Hiu T. Leung, and R. Frederick Westbrook \\ School of Psychology, University of New South Wales, Sydney 2052, Australia
}

\begin{abstract}
This series of experiments used rats to compare counterconditioning and extinction of conditioned fear responses (freezing) with respect to the effects of a context shift. In each experiment, a stimulus was paired with shock in context $A$, extinguished or counterconditioned through pairings with sucrose in context $B$, and then tested for renewal outside of context B. Counterconditioned fear responses exhibited greater ABA renewal than extinguished fear responses. This result was observed using a between-subjects design (Experiment 1 ) and a within-subject design in which counterconditioned and extinguished stimuli were equated in all respects other than their signaling of sucrose (Experiment 2). Counterconditioned fear responses also exhibited greater $A B C$ renewal than extinguished fear responses (Experiment 3). This result was observed using a within-subject design in which context $C$ was identical to context $B$ in terms of its associative history, and when counterconditioned and extinguished CSs were tested in compounds matched for their association with both shock and sucrose (Experiment 4). These results are consistent with models which hold that context regulates expression of associations formed in counterconditioning and extinction, and allow the level of regulation to be greater following counterconditioning than extinction, as noted in previous studies.
\end{abstract}

One way to eliminate conditioned fear is extinction. A relatively innocuous stimulus, such as a tone, is first paired with an innate source of danger (typically, brief but aversive footshock in rodents). These pairings produce an association between the tone [conditioned stimulus (CS)] and the aversive foot shock [unconditioned stimulus (US)] that is expressed on subsequent presentations of the CS in a range of defensive responses indicative of fear in people. Extinction consists in repeated presentations of the CS in the absence of the aversive US. The fear responses, such as freezing, elicited by the CS decline across these presentations and eventually cease. Fear of the CS is said to be extinguished. It is now well-established that the learning produced by conditioning survives extinction in spite of the fact that the CS failed to elicit fear responses. For example, the fear response that has been extinguished can be restored by testing the CS outside the context where extinction occurred (renewal), interpolating US alone presentations between extinction and testing (reinstatement), or testing the CS sometime after extinction (spontaneous recovery). These fear restoration phenomena imply that extinction involves new learning that inhibits retrieval and/ or expression of the original learning in fear responses (Bouton 1991, 1993, 1994, 2002, 2004; Delamater 2004; Delamater and Westbrook 2014).

A second way to eliminate conditioned fear is counterconditioning. Here, the CS is again presented in the absence of the aversive shock US. However, in contrast to extinction where the CS is presented alone, in counterconditioning the CS is paired with an attractive US, such as food for a hungry rat. The fear responses elicited by the CS decline across these presentations and are replaced with appetitive responses, such as approach to the food magazine (see Dickinson and Pearce 1977). Moreover, Bouton and colleagues have reported that a counterconditioned CS exhibits the same forms of fear restoration as an extinguished CS. A CS paired with shock in one context, A, and then paired with food in a second context, B, elicits appetitive responses (head jerk) when tested in context B but fear responses (freezing) when tested

\section{Corresponding author: f.westbrook@unsw.edu.au}

Article is online at http://www.learnmem.org/cgi/doi/10.1101/lm.040659.115. in context A (renewal) (Peck and Bouton 1990). The fear responses that have been replaced by appetitive responses across pairings of the aversive CS and an attractive US are restored when the CS is tested after shock alone presentations (reinstatement) (Brooks et al. 1995). Finally, a CS paired with an aversive US and then with an attractive US elicits appetitive responses when tested shortly after counterconditioning but fear responses when tested sometime after counterconditioning (spontaneous recovery) (Bouton and Peck 1992). These results show that the original learning survives counterconditioning in spite of the fact that the CS elicited approach rather than fear responses. They imply that the learning produced by counterconditioning, like that produced by extinction, inhibits retrieval and/or expression of the original learning in fear responses. It is worth noting that renewal and spontaneous recovery of the first-learned association have also been demonstrated in appetitive-to-aversive counterconditioning procedures (Peck and Bouton 1990; Bouton and Peck 1992), showing that the effects of a context change and lapse of time are not specific to the shift from aversive conditioning in stage 1 to appetitive conditioning in stage 2 .

Thus, an extinguished and a counterconditioned CS both exhibit renewal, reinstatement, and spontaneous recovery of fear. A theoretically and clinically important question is which type of CS elicits the greater fear restoration. On the one hand, counterconditioning converts an aversive CS from one that elicits fear responses to one that elicits approach responses. Hence, this appetitive association may render the counterconditioned CS more resistant to the return of fear than an extinguished CS (for a similar argument in the case of appetitive-to-aversive counterconditioning, see Van Gucht et al. 2013). On the other hand, counterconditioning may facilitate the discrimination between the two meanings of the CS (danger and approach), and, therefore, better preserve the original meaning of the CS than extinction. Hence,

(C) 2016 Holmes et al. This article is distributed exclusively by Cold Spring Harbor Laboratory Press for the first 12 months after the full-issue publication date (see http://learnmem.cshlp.org/site/misc/terms.xhtml). After 12 months, it is available under a Creative Commons License (Attribution-NonCommercial 4.0 International), as described at http://creativecommons.org/ licenses/by-nc/4.0/. 
Table 1. Summary of designs for each experiment

\begin{tabular}{|c|c|c|c|}
\hline \multicolumn{4}{|c|}{ Experiment 1} \\
\hline Group & Stage 1 & Stage 2 & Test \\
\hline $\begin{array}{l}C C \\
\text { Ext }\end{array}$ & $\begin{array}{l}\text { Cxt A: CS1-shock } \\
\text { Cxt A: CS1-shock }\end{array}$ & $\begin{array}{l}\text { Cxt B: CS1-sucrose } \\
\text { Cxt B: CS1-nothing }\end{array}$ & $\begin{array}{l}\text { Cxt A: CS1? } \\
\text { Cxt A: CS1? }\end{array}$ \\
\hline \multicolumn{4}{|c|}{ Experiment 2} \\
\hline $\begin{array}{l}\text { Cxt A: CS1-shock } \\
\text { Cxt A: CS2-shock }\end{array}$ & $\begin{array}{l}\text { Cxt B: CS1-sucrose } \\
\text { Cxt B: CS2-nothing }\end{array}$ & & $\begin{array}{l}\text { Cxt A: CS1? } \\
\text { Cxt A: CS2? }\end{array}$ \\
\hline \multicolumn{4}{|c|}{ Experiment 3} \\
\hline $\begin{array}{l}\text { Cxt A: CS1-shock } \\
\text { Cxt A: CS2-shock } \\
\text { Cxt A: CS3-shock } \\
\text { Cxt A: CS4-shock }\end{array}$ & $\begin{array}{l}\text { Cxt B: CS1-sucrose } \\
\text { Cxt B: CS2-nothing } \\
\text { Cxt C: CS3-sucrose } \\
\text { Cxt C: CS4-nothing }\end{array}$ & & $\begin{array}{l}\text { Cxt B and C: CS1? } \\
\text { Cxt B and C: CS2? }\end{array}$ \\
\hline \multicolumn{4}{|c|}{ Experiment 4} \\
\hline $\begin{array}{l}\text { Cxt A: CS1-shock } \\
\text { Cxt A: CS2-shock } \\
\text { Cxt A: CS3-shock } \\
\text { Cxt A: CS4-shock }\end{array}$ & $\begin{array}{l}\text { Cxt B: CS1-sucrose } \\
\text { Cxt B: CS2-nothing } \\
\text { Cxt C: CS3-sucrose } \\
\text { Cxt C: CS4-nothing }\end{array}$ & & $\begin{array}{l}\text { Cxt B and C: CS1CS4? } \\
\text { Cxt B and C: CS2CS3? }\end{array}$ \\
\hline
\end{tabular}

CS1, CS2, CS3, and CS4 are tone, noise, steady light, and flashing light-conditioned stimuli (counterbalanced within modality, within each experiment). (CC) = counterconditioning; (Ext) extinction; (Cxt) context; (CS) conditioned stimulus.

counterconditioning may be less resistant to the return of fear than extinction (Redish et al. 2007).

The present experiments used between- and within-subject designs to compare the effectiveness of extinction and counterconditioning in protecting against the return of fear. In each experiment, the manipulation used to restore fear was testing the CS outside the context where fear had been eliminated. The aim of the initial experiments was to determine whether counterconditioned fear responses are more or less sensitive to a context shift than extinguished fear responses. These experiments used a so-called ABA protocol in which rats were exposed to CS-shock pairings in context $A$, subjected to extinction or counterconditioning in context B and finally tested in context A. The subsequent experiments examined the generality of effects observed in the initial experiments, and sought to identify the specific mechanism by which a context shift yields these effects. They used a so-called ABC protocol. Four CSs were each paired with shock in context A, two were subjected to counterconditioning, one in context $\mathrm{B}$ and the other in context $\mathrm{C}$, while the other two were subjected to extinction, one in context $B$ and the other in context C. The question of interest was the levels of renewal when the CSs were tested outside the context where they had been counterconditioned or extinguished: more specifically, whether CSs that were counterconditioned or extinguished in one context (e.g., context B) underwent renewal when tested in the context where other CSs had been counterconditioned or extinguished (context C), and whether the level of this renewal was greater for the counterconditioned than the extinguished CSs.

\section{Results}

\section{Experiment 1}

Experiment 1 used a between-subjects design to compare the effects of a context shift on extinguished and counterconditioned fear responses. The design is shown in Table 1 . Two groups of rats were exposed to CS-shock pairings in context A, presentations of the CS in the absence of shock in context B, and finally, test presentations of the CS alone in A. The two groups differed in their treatments during training in context B. For one group, Group
EXT, conditioned fear responses were extinguished across repeated presentations of the CS alone. For the other group, Group CC, conditioned fear responses were counterconditioned across repeated pairings of the aversive CS with an appetitive US, sucrose.

Figure 1 (left panel) shows the levels of freezing and time spent in magazine across blocks of four trials in context B. Rats in Group EXT froze more to the CS than those in Group CC, $F_{(1,6)}=29.29, P<0.01,95 \%$ CI $[-3.17,-1.20], d=3.83$. Levels of freezing decreased across stage $2, F_{(1,6)}=32.73, P<0.01,95 \%$ CI $[-1.92,-0.77], d=1.07$, indicating that extinction and counterconditioning gradually eliminated freezing. There was no statistically significant group $\times$ trials interaction, $F<4.7, F \mathrm{c}=5.99$, indicating that the differences between the levels of freezing in the two groups persisted across stage 2 . There was also no significant difference between the two groups in pre-CS levels of freezing, $F<1$. Rats in Group CC, but not in Group EXT, progressively increased the amount of time spent in the magazine during CS presentations, $F_{(1,6)}=7.56, P<0.05,95 \%$ CI $[-1.63,-0.09]$, $d=2.98$, and rats in Group CC spent more time in the magazine than rats in Group EXT, $F_{(1,6)}=20.32, P<0.05,95 \%$ CI $[-3.78$, $-1.12], d=3.19$.

Figure 1 (right panel) shows the levels of freezing across blocks of two CS presentations on test in context A. The statistical analysis confirmed what is clear from inspection of the figure. Rats that had received pairings of the CS and sucrose (Group CC) in context B froze significantly more when tested with the CS in context A than rats in Group EXT that had received CS alone presentations in context $\mathrm{B}, F_{(1,14)}=22.22, P<0.001,95 \% \mathrm{CI}[-2.62$, $-0.98], d=14.77$. There was no significant decline in freezing across CS trials, $F_{(1,14)}=2.46$, and no significant group $\times$ trials interaction, $F<1$, indicating that the differences in the levels of freezing between the two groups persisted across the test presentations. There was no significant difference between Group EXT and Group CC in the overall level of pre-CS freezing, $F<1$.

This experiment has confirmed that fear responses are restored when a CS is paired with shock in context A, paired with sucrose in context B and tested in context A (Peck and Bouton 1990). Rats that had been exposed to CS-shock pairings in context A ceased to freeze and came to approach the magazine when 

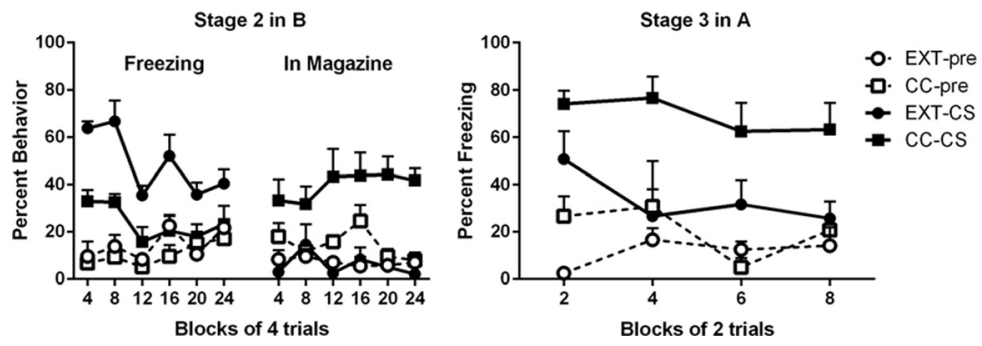

Figure 1. Experiment 1. (Left panel) Mean (+SEM) levels of freezing and time spent in magazine during pre-CS and CS periods across blocks of trials in Experiment 1. (Right panel) Mean (+SEM) levels of freezing during pre-CS and CS periods across blocks of two test trials in Experiment 1.

the CS was paired with sucrose in context B. However, these rats exhibited a high level of freezing when subsequently tested with the CS in context A (it failed to extinguish across eight presentations of the CS alone), indicating a strong expectation of the aversive US. These rats (Group CC) not only froze when tested with the $\mathrm{CS}$ in context A but also froze more than rats that had been exposed to CS alone presentations in context B (Group EXT). That is, the amount of renewal observed after counterconditioning was greater than that observed following extinction.

\section{Experiment 2}

In the previous experiment, the group subjected to extinction in stage 2, Group EXT, was exposed to CS alone presentations in context $\mathrm{B}$, while the group subjected to counterconditioning in stage 2, Group CC, was exposed to CS-sucrose pairings in this context. Thus, the two groups differed not only in the contingency between the CS and sucrose during stage 2 in B. They also differed in that one group was exposed to sucrose while the other was not. This experience of sucrose in Group CC may have rendered contexts B and A more dissimilar than in Group EXT, resulting in less transfer of stage 2 learning to the test context, and therefore, more renewal.

The present experiment addressed this issue using a withinsubject design (Table 1). The design consisted in exposing rats to two CSs (CS1 and CS2), each of which was paired with the shock US in context A. Then the rats were moved to context B where training consisted in pairing one of the CSs, CS1, with the sucrose US while additionally presenting CS2 alone. Finally, rats were returned to context A for testing with CS1 and CS2. If the difference in renewal in the previous experiment was due to between-group differences in the perceived similarity of contexts $\mathrm{B}$ and $\mathrm{A}$, and therefore, transfer of stage 2 learning in context $B$ to the test context $\mathrm{A}$, there should be no such difference in renewal of freezing to the CS paired with sucrose in stage 2, CS1 (counterconditioned), and the CS presented alone in stage 2 , CS2 (extinguished).

Fear conditioning of CS1 and CS2 in context A proceeded without incident. Figure 2 shows the levels of freezing and time spent in magazine across blocks of four CS presentations in context B (left panel), and the levels of freezing across blocks of two CS presentations on test in context A (right panel). Freezing to the CSs decreased across CS1-sucrose and CS2-alone presentations in context B, $\quad F_{(1,7)}=91.5, \quad P<0.001, \quad 95 \% \quad$ CI $[-3.44,-2.07], d=3.04$. Critically, the overall level of freezing was lower during CS1 than CS2, $F_{(1,7)}=72.51, P<0.001$,
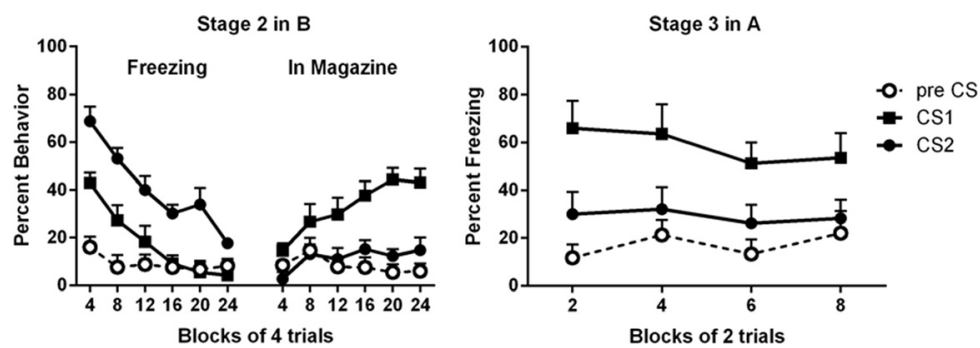

Figure 2. Experiment 2. (Left panel) Mean levels of freezing and time spent in magazine across blocks of four trials in context $B$. (Right panel) Mean levels of freezing across blocks of two trials on test in context $A$. The error bars in each panel show two standard errors of the difference between the mean levels of responding (freezing or time in magazine) to CS1 and CS2 (Loftus and Masson 1994). 
CS4, were each paired with shock in context A. CS1 was then paired with sucrose while CS2 was presented alone in a second context, B. CS3 was paired with sucrose while CS4 was presented alone in a third context, C. Finally, CS1 and CS2 were tested in the context where they had been counterconditioned or extinguished, B, or in the context where CS3 and CS4 had been counterconditioned or extinguished, $\mathrm{C}$. This design equates the training and test contexts, $\mathrm{B}$ and $\mathrm{C}$, with respect to their associative history; hence, any renewal observed using this design must arise as a consequence of the change in context-CS relations across the shift from stage 2 in B to stage 3 (test) in C. It was anticipated that this shift would renew counterconditioned fear responses to CS1 and extinguished fear responses to CS2. The question of interest was whether counterconditioned fear responses to CS1 exhibited more or less renewal across this shift than extinguished fear responses to CS2.

Fear conditioning of the four CSs in context A proceeded without incident. Figure 3 shows the levels of freezing and time spent in magazine across presentations of CS1 and CS2 in context $\mathrm{B}$ (left panel) and CS3 and CS4 in context C (middle panel). In each context, freezing to the CSs declined across blocks of trials, $F_{(1,7)}=422.51, P<0.001,95 \%$ CI $[-5.04,-4.00], d=5.55$. Overall, the counterconditioned CSs, CS1, and CS3, evoked less freezing than the extinguished CSs, CS2, and CS4, $F_{(1,7)}=$ 150.45, $P<0.001,95 \%$ CI $[-1.59,-1.08], d=4.87$. There was no significant difference in the overall level of freezing in contexts $\mathrm{B}$ and $\mathrm{C}, F<1$, and the two- and three-way interactions between the factors of context, stimulus and block were not significant, Fs $<2.7$. Conversely, time in the magazine increased across stage 2 training, $F_{(1,7)}=137.81, P<0.001,95 \%$ CI $[-2.88$, -1.91 ],$d=4.15$. This increase was selective to the CSs paired with sucrose, CS1 in context B and CS3 in context C, as evidenced by a significant stimulus $\times$ block interaction, $F_{(1,7)}=248.44, P<$ $0.001,95 \%$ CI $[-1.88,-1.39], d=4.42$. Consequently, the overall level of time in the magazine was greater for the CSs paired with sucrose, CS1 and CS3, than for the CSs presented alone, CS2 and CS4, $F_{(1,7)}=444.28, P<0.001,95 \%$ CI $[-3.24,-2.59], d=13.91$. There was no significant difference in overall time in magazine in contexts B and C, $F<1.9$, and the remaining two- and three-way interactions between the factors of context, stimulus and block were not significant, $F \mathrm{~s}<1.1$.

The right panel of Figure 3 shows the mean levels of freezing to the context, CS1 and CS2 during the tests in context B and context $\mathrm{C}$. The CSs evoked little freezing when tested in the context, $\mathrm{B}$, where they had been counterconditioned (CS1) or extinguished (CS2), and more freezing in the context, C, where CS3 had been counterconditioned and CS4 had been extinguished. Critically, inspection suggests that the levels of freezing produced by the context shift between $\mathrm{B}$ and $\mathrm{C}$ were greater for the counter- conditioned CS1 than the extinguished CS2. This was confirmed by the statistical analysis which revealed significant main effects of context, $F_{(1,7)}=41.33, P<0.001,95 \%$ CI $[-2.48,-1.15], d=$ 2.48 , and stimulus, $F_{(1,7)}=35.89, P<0.01,95 \%$ CI $[0.53,1.23]$, $d=2.66$, and, importantly, a significant context $\times$ stimulus interaction, $F_{(1,7)}=62.23, P<0.001,95 \%$ CI $[-1.54,-0.83]$. The source of the interaction was examined using contrasts which revealed that rats froze less to CS1 than CS2 in the context, B, where they had been counterconditioned and extinguished, respectively, $F_{(1,7)}=17.94, P<0.01,95 \%$ CI $[-1.33,-0.38], d=1.56$, but froze more to CS1 than CS2 when tested in context C, where CS3 and CS4 had been counterconditioned and extinguished, respectively, $F_{(1,7)}=51.27, P<0.001,95 \%$ CI $[1.59,3.15], d=3.68$. These results show that the counterconditioned CS elicited less fear than the extinction CS in their training context but elicited more fear than the extinguished CS outside that context.

This experiment has replicated the previous findings that a counterconditioned CS elicits more freezing than an extinguished CS when each are tested outside their training context. In contrast to the previous experiments where the CSs were moved from their training context to the fear conditioning context (ABA), here the training and test contexts differed only with respect to the specific counterconditioned and extinguished CSs presented in those contexts $(\mathrm{ABC})$. The fact that the counterconditioned CS underwent greater renewal than the extinguished CS when the training and test contexts (B and C, respectively) were matched for their associative history shows that, while both CSs were sensitive to context shift, the counterconditioned CS was more sensitive than the extinguished CS to any shift.

\section{Experiment 4}

The previous experiments have shown that a context shift between training and test is more effective in renewing counterconditioned than extinguished freezing, and that this difference is also observed when the training and test contexts are equated in terms of their associative history. In each experiment, the counterconditioned or extinguished CSs were tested under equivalent circumstances, i.e., in the absence of any US presentations. However, these equivalent circumstances may have differentially affected the two CSs: e.g., in the case of the counterconditioned $\mathrm{CS}$, the absence of expected sucrose may have generated an aversive state of frustration, resulting in potentiated expression of any residual association between that CS and shock, and therefore, greater restoration of freezing to this CS than the extinguished CS.

The present experiment addressed this issue using a withinsubject design in which extinguished and counterconditioned CSs were both tested in the absence of expected sucrose (see
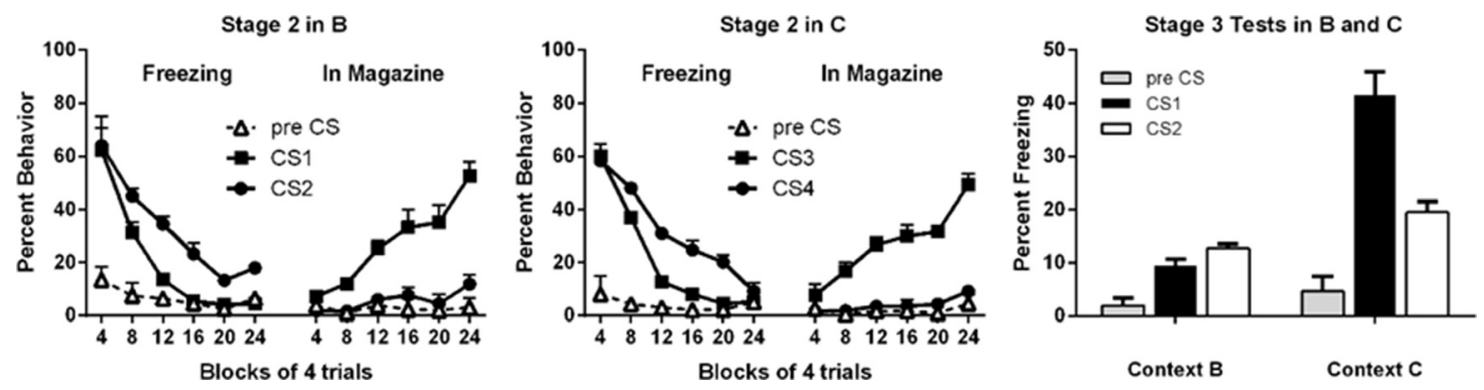

Figure 3. Experiment 3. (Left panel) Mean levels of freezing and time spent in magazine across blocks of four trials during stage 2 training in context $B$. (Middle panel) Mean levels of freezing and time spent in magazine across blocks of four trials during stage 2 training in context C. (Right panel) Mean levels of freezing across blocks of two trials on test in context $B$ or $C$. The error bars in each panel show two standard errors of the difference between the mean levels of responding (freezing or time in magazine) to the CSs (Loftus and Masson 1994). 
Table 1). In stage 1, four CSs, two auditory, CS1 and CS3, and two visual, CS2 and CS4, were each paired with footshock in context A. In stage 2, CS1 and CS2 were counterconditioned and extinguished, respectively, in context B; while CS3 and CS4 were counterconditioned and extinguished, respectively, in context C. Finally, in stage 3, rats were tested under conditions of extinction with two compounds, one composed of CS1 and CS4 and the other of CS2 and CS3, in contexts B and C. Each compound thus contained one counterconditioned (CS1 and CS3) and one extinguished CS (CS2 and CS4) and each compound was tested in the absence of any other events. If the difference in responding to counterconditioned and extinguished CSs observed in the previous experiments was due to the fact that the counterconditioned CS (but not extinguished CS) was tested in the absence of expected sucrose, each of the test compounds in the present experiment should evoke equivalent levels of performance in each context: each compound contains a CS that had been paired with sucrose (CS1 and CS3), and therefore, each of the target CSs, CS1 and CS2, is tested in the absence of expected sucrose. If, however, the difference in responding to counterconditioned and extinguished CSs in the previous experiments arose as a consequence of the context shift, the test compounds in the present experiment should evoke different levels of performance in each context. This is because the relation between the counterconditioned and extinguished elements of each compound and the context remain either the same or different from training to test: the counterconditioned element (CS1) of the CS1CS4 compound was trained in context B whereas the extinguished element (CS4) was trained in context $\mathrm{C}$; the counterconditioned element (CS3) of the CS2CS3 compound was trained in context $\mathrm{C}$, whereas the extinguished element (CS2) was trained in context B. If the counterconditioned element of each compound undergoes more renewal when tested outside its training context, then freezing should be greater when the CS1CS4 compound is tested in context C than in context B, and freezing should also be greater when the CS2CS3 compound is tested in context $\mathrm{B}$ than in context $\mathrm{C}$.

Fear conditioning of the four CSs in context A proceeded without incident. Figure 4 shows the levels of freezing and time spent in magazine across presentations of CS1 and CS2 in context B (left panel) and CS3 and CS4 in context C (middle panel). In each context, freezing to the CSs declined across blocks of trials, $F_{(1,7)}=590.56, P<0.001,95 \%$ CI $[-5.10,-4.19], d=11.44$. Overall, the counterconditioned CSs, CS1 and CS3, evoked less freezing than the extinguished CSs, CS2 and CS4, $F_{(1,7)}=$ 108.26, $P<0.001,95 \%$ CI $[-1.69,-1.06], d=3.85$. There was no significant difference in the overall level of freezing in contexts $\mathrm{B}$ and $\mathrm{C}, F<3.9$, and the two- and three-way interactions between the factors of context, stimulus and block were not significant, $F s<1.3$. Conversely, time in the magazine increased across stage
2 training, $F_{(1,7)}=161.60, P<0.001,95 \%$ CI $[-2.65,-1.82], d=$ 4.09. This increase was selective to the CSs paired with sucrose, CS1 in context B and CS3 in context C, as evidenced by a significant stimulus $\times$ block interaction, $F_{(1,7)}=123.96, P<0.001,95 \%$ CI $[-2.17,-1.41], d=7.80$. Consequently, the overall level of time in the magazine was greater for the CSs paired with sucrose, CS1 and CS3, than for the CSs presented alone, CS2 and CS4, $F_{(1,7)}=311.0, \quad P<0.001,95 \%$ CI $[-3.44,-2.63], d=9.69$. There was no significant difference in overall time in magazine in contexts B and C, $F<1$, and the remaining two- and three-way interactions between the factors of context, stimulus and block were not significant, $F \mathrm{~s}<1.4$.

The right panel of Figure 4 shows the mean levels of freezing to the CS1CS4 and CS2CS3 compounds during test sessions. The pattern of freezing to the compounds differed in contexts B and C. In each context, freezing was greater to the compound which contained the CS that had been counterconditioned elsewhere rather than the CS that had been extinguished elsewhere. In context $\mathrm{B}$, the compound, CS2CS3, containing the CS counterconditioned in $\mathrm{C}$, that is CS3, produced more freezing than the compound, CS1CS4, containing the CS extinguished in C, that is, CS4. Conversely, in context C, the compound, CS1CS4, containing the CS counterconditioned in $\mathrm{B}$, that is, CS1, produced more freezing than the compound, CS2CS3, containing the CS that had been extinguished in B, that is, CS2. These impressions were confirmed statistically. The main effects of context and stimulus were not significant, $F s<1.1$, however, there was a significant interaction between these factors, $F_{(1,7)}=101.14, P<$ $0.001,95 \%$ CI $[-2.26,-1.40]$. The source of this interaction was examined using contrasts which revealed that CS1CS4 evoked less freezing than CS2CS3 in context $\mathrm{B}, F_{(1,7)}=211.79, P<0.001$, $95 \%$ CI $[-5.14,-3.71], d=6.11$, and conversely, that CS1CS4 evoked more freezing than CS2CS3 in context C, $F_{(1,7)}=16.13$, $P<0.001,95 \%$ CI $[0.77,2.96], d=1.86$.

This experiment has replicated the finding that a counterconditioned CS exhibits more renewal than an extinguished CS, confirmed that the effect persists when the training and test contexts are equated with respect to their associative history, and shown that this effect is also present when counterconditioned or extinguished CSs are tested in compounds matched for their association with both shock and sucrose. These results thus demonstrate that a counterconditioned CS is subject to greater renewal of its original fear association than an extinguished CS.

\section{Discussion}

These experiments have shown that counterconditioning affords less protection than extinction against renewal of fear by a
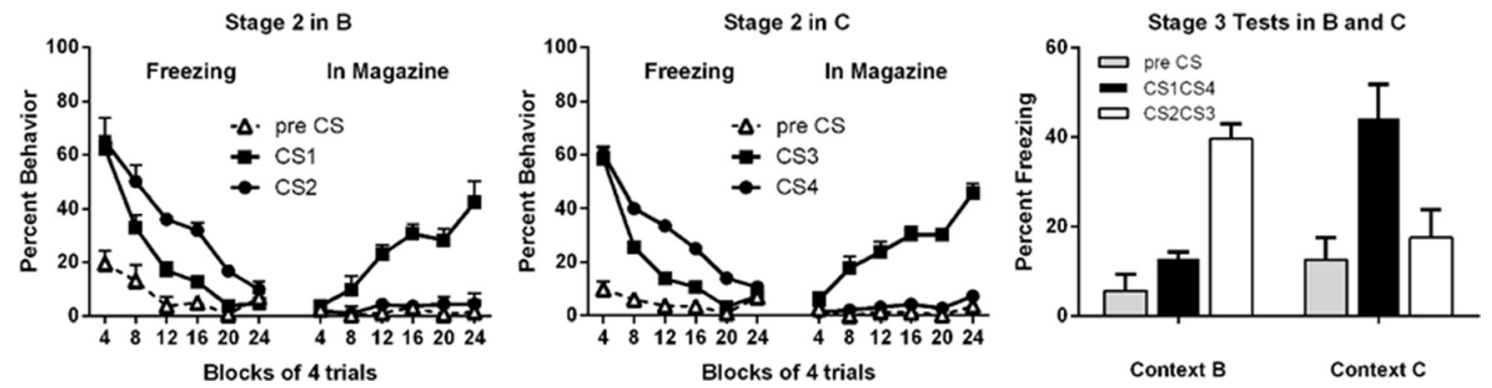

Figure 4. Experiment 4. (Left panel) Mean levels of freezing and time spent in magazine across blocks of four trials during stage 2 training in context $B$. (Middle panel) Mean levels of freezing and time spent in magazine across blocks of four trials during stage 2 training in context $C$. (Right panel) Mean levels of freezing across blocks of two trials on test in context $B$ or $C$. The error bars in each panel show two standard errors of the difference between the mean levels of responding (freezing or time in magazine) to the CSs (Loftus and Masson 1994). 
context shift. Experiment 1 used a between-subject ABA design where two groups were exposed to CS-shock pairings in context A, then one group received pairings of the CS and sucrose while the other group was given CS alone presentations in context B. The test in context A revealed that the CS elicited more freezing in the counterconditioned than the extinguished group. Experiment 2 used a within-subject ABA design in which two CSs were each paired with shock in context A. Then one CS was paired with sucrose and the other presented alone in context $B$. The counterconditioned CS again elicited more freezing than the extinguished CS when both were tested in context A, showing that the difference in renewal observed in Experiment 1 was not due to an increased discriminability between the sucrose associated B context and the shock associated A context.

Experiments 3 and 4 assessed whether the difference in renewal was specific to a shift from the context, B, where sucrose had been presented, to the context, $\mathrm{A}$, where shock had occurred. They used within-subject ABC designs in which four CSs were each paired with shock in context $A$. Then rats were exposed to contexts B and C. In context B, one CS (CS1) was counterconditioned with sucrose while a second CS (CS2) was extinguished; in context C, a third CS (CS3) was counterconditioned with sucrose while the fourth CS (CS4) was extinguished. Contexts B and $\mathrm{C}$ were thus equated with respect to counterconditioning and extinction, differing only in the specific CSs counterconditioned or extinguished. Experiment 3 found that testing the CSs outside the context where they had been counterconditioned or extinguished renewed freezing responses and, critically, that a CS counterconditioned in one context (e.g., CS1 in context B) elicited more freezing than an extinguished CS (CS2 in context B) when tested in context C. Experiment 4 tested compounds composed of counterconditioned and extinguished elements where one or other element of the compounds was context-shifted. It found that the compound which contained a context-shifted counterconditioned element elicited more renewal than the compound which contained a context-shifted extinguished element, confirming that counterconditioning affords less protection than extinction against fear renewal by any context shift.

How does a context shift renew the fear responses that have been eliminated by extinction or counterconditioning and why is renewal greater after counterconditioning than extinction? The various theories of extinction and renewal differ in their capacity to explain the present findings. At one end of the spectrum are theories which hold that the error produced by the omission of an expected shock results in inhibitory changes to a CS and its initially neutral extinction context (as was the case in the present study where a CS was conditioned in A and extinguished in B; e.g., Rescorla and Wagner 1972). Critically, the inhibition accrued to the context ensures some residual strength for the CS at the end of extinction. As such, these theories anticipate ABA renewal: the shift from extinction in B to test in A removes the inhibitory influence of the context, and thus, permits expression of the residual CS strength. However, they do not anticipate ABC renewal where $\mathrm{B}$ and $\mathrm{C}$ are matched for their associative history: the shift from $B$ to $C$ removes the inhibitory influence of the $B$ context, but the equivalent inhibition accrued to $\mathrm{C}$ should continue to mask expression of the residual CS strength. They also fail to accommodate the finding of greater renewal to a counterconditioned than extinguished CS (independently of the type of renewal): if anything, they predict that counterconditioning should be more effective than extinction in producing associative loss (due to the surprising presentation of unexpected sucrose), and therefore, less effective than extinction in protecting a CS from renewal.

Other theories that attribute extinction to associative loss include additional features which enable them to accommodate the present findings. For example, Rescorla (2008) has argued that, during extinction, inhibition accrues to a unique configural cue, $\mathrm{X}$, which represents the conjunction of a CS in its extinction context (see also Harris et al. 2000; Holmes and Westbrook 2013; Holmes et al. 2014). Hence, presentation of an extinguished CS inside its extinction context yields low levels of performance, while presentation of an extinguished CS in a different context, one matched with the extinction context for its associative history, removes the influence of inhibition accrued to $X$ and renews performance (in either ABA or ABC designs). This analysis implies that the level of renewal is proportional to the amount of inhibition accrued to X; and applied to the present findings, that counterconditioning produces proportionally greater inhibition to $\mathrm{X}$ than does extinction. This might occur because, in counterconditioning, $X$ uniquely predicts the omission of expected shock and occurrence of unexpected sucrose. Therefore, relative to extinction, $\mathrm{X}$ undergoes greater change in counterconditioning, and a counterconditioned CS exhibits more renewal.

Other theories attribute extinction to both associative change and discrimination between the past and present meaning of the CS (Redish et al. 2007; Larrauri and Schmajuk 2008). Some of these theories link each of these processes to surprise/error (e.g., Redish et al. 2007): that is, a large error can produce large amounts of change in extinction (erasure); but once some evidentiary threshold is reached (i.e., once this discrimination is complete), further associative change ceases to occur. However, the effects of error on associative change and discrimination are at least partly independent, meaning that a large error can yield rapid discrimination and very little associative change. Hence, across a certain range of parameters, these models provide a reasonable account of the present findings. During the initial training in context $\mathrm{B}$, the surprise engendered by the omission of expected shock is magnified by the occurrence of the unexpected sucrose in counterconditioning. This increase in surprise facilitates the discrimination between past and present circumstances (i.e., state-splitting), resulting in more effective preservation of the association formed in conditioning. Hence, relative to an extinguished CS, a counterconditioned CS exhibits greater renewal with a context shift, and independently of the type of shift (i.e., $\mathrm{ABA}$ or $\mathrm{ABC}$ renewal).

Bouton's (1993, 1994, 2002, 2004) retrieval interference model provides an alternative account of renewal in all its various forms and accommodates aspects of the present findings. According to this model, the CS-shock association is encoded relatively independently of the context in which it occurs, and hence, transfers readily between contexts. In contrast, during counterconditioning or extinction, ambiguity engendered by the absence of the expected US increases attention to contextual cues; and hence, the new learning that occurs (e.g., CS-sucrose or CS-no US) is encoded with respect to these cues. As such, the model anticipates renewal: a context shift undermines retrieval of the context-dependent CS-sucrose or CS-no US association, and therefore, its capacity to interfere with expression of the context-independent CS-US association. However, in its present form, it does not allow for variation in the strength of hierarchical associations between the context and CS-sucrose or CS-no US associations, and therefore, does not anticipate a difference in renewal following counterconditioning or extinction. The model could accommodate the finding of greater renewal to a counterconditioned CS if modified to allow the level of ambiguity during counterconditioning or extinction to control the level of attention to the context. As noted above, counterconditioning and extinction are equivalent with respect to the absence of expected shock, but differ in that the former involves presentation of unexpected sucrose. As such, the shift from conditioning to counterconditioning engenders more ambiguity than the shift 
from conditioning to extinction, and this may provide the basis for stronger contextual encoding (and therefore, greater context specificity) of associations formed in counterconditioning; hence greater renewal.

Three additional points are worth noting in relation to the experiments in this study. First, the level of renewal following extinction was relatively low compared with other studies. This may have been due to the fact that, prior to the first stage of fear conditioning in context $\mathrm{A}$, all rats were pretrained to drink sucrose in context B (but not context A). Pretraining with sucrose in context $B$ may have resulted in less attention to the specific features of context B (as rats spent a lot of time with their heads in the magazine), and therefore, poorer discrimination between extinction of the CS in context B and testing of the CS in a different context (A or C): hence the relatively low levels of renewal following extinction. Second, an alternative explanation of the difference in test responding between counterconditioning and extinction is that the presence of paired sucrose in counterconditioning acts as a retrieval cue for inhibition of the conditioned freezing response. If true, then the difference between a counterconditioned and extinguished CS should be observed when rats are tested in any context, including the one in which stage 2 training occurred. However, Experiment 3 showed that this is not the case: there was no difference between the counterconditioned and extinguished CSs when they were tested inside the context where they had been subjected to counterconditioning or extinction, context B. Hence, the difference in test responding between counterconditioned and extinguished CSs requires a change in the physical context between training in stage 2 and testing in stage 3 .

Third, during stage 2 training in each experiment, conditioned freezing responses declined more rapidly when the CS was subjected to counterconditioning than extinction. Together with the pattern of test results, this suggests that counterconditioning is more effective than extinction in eliminating conditioned fear responses, but less effective than extinction in protecting against their renewal. According to the view that protection from renewal requires learned inhibition of fear responses (Rescorla 2006; Leung et al. 2012; Holmes and Westbrook 2013), a potential implication of this pattern of results is that, because counterconditioning leads to a very rapid elimination of conditioned fear responses (possibly through peripheral response interactions which occur during acquisition of the new magazine entry response), it reduces the opportunity for learned inhibition of those fear responses. But here again, this explanation implies that a counterconditioned CS should evoke more freezing than an extinguished CS when testing occurs inside the context of stage 2 training, B. This was not observed in Experiment 3.

The finding that a counterconditioned CS exhibits more renewal than an extinguished CS appears to conflict with a recent report that an aversive CS paired with a novel stimulus exhibits less spontaneous recovery than an aversive CS presented alone in extinction (Dunsmoor et al. 2015). However, these two studies differed with respect to the context in which testing occurred: rats were tested outside the context of stage 2 training in the present study, and inside the context of stage 2 training in the study by Dunsmoor et al. This pattern of findings suggests that the context shift between training in stage 2 and testing in stage 3 is indeed germane to the results obtained in the present study. It remains to be determined whether a counterconditioned CS exhibits more or less spontaneous recovery than an extinguished CS, and conversely, whether a CS paired with a novel stimulus in extinction exhibits more or less renewal than a CS presented alone in extinction.

Finally, the present findings have implications for the treatment of anxiety disorders like post-traumatic stress. A component of this treatment is cue exposure, which involves patients, aided by the clinician, learning to inhibit their fear in the presence of cues that provoke that fear. It has previously been suggested that treatment efficacy (i.e., resistance to relapse) is undermined by the presence of safety signals across the course of cue exposure, as experience of fear is necessary for learned fear inhibition (see Lovibond et al. 2000, 2009). The present findings suggest that treatment efficacy may also be reduced when a patient's responses in cue exposure are explicitly rewarded, as fear inhibition under these circumstances may exhibit greater specificity to the cue exposure context.

\section{Materials and Methods}

\section{Subjects}

Subjects were experimentally naïve adult male Sprague Dawley rats (Rattus norvegicus), weighing between 380 and $430 \mathrm{~g}$ at the beginning of the experiment. They were obtained from a commercial supplier (Animal Research Centre) and housed in opaque plastic boxes $(22 \mathrm{~cm}$ height $\times 67 \mathrm{~cm}$ length $\times 40 \mathrm{~cm}$ width). There were eight rats per box. The boxes were kept in an airconditioned colony room maintained on a 12:12 light-dark cycle (lights on at 7:00 a.m.). Chow was freely available in the home cage. Access to water was reduced to $2 \mathrm{~h}$ per $\mathrm{d} 7 \mathrm{~d}$ prior to the beginning of the experiment and this schedule was maintained throughout the experiment. Access to water occurred after the final session each day. This schedule maintained rats at $\sim 90 \%$ of their free-feeding weights. Each rat was handled for 2-3 min each day for $4 \mathrm{~d}$ prior to the start of the experiment. All experimental procedures occurred during the light phase (between 9 a.m. and 7 p.m.). The procedures used were consistent with the ethical guidelines established by the American Psychological Association and were approved by the Animal Care and Ethics Committee of the University of New South Wales.

\section{Apparatus}

Experiments 1 and 2 were conducted in two sets of four chambers. Each chamber of one set, designated A, measured $33 \mathrm{~cm}$ (height) $\times 31 \mathrm{~cm}$ (length) $\times 26 \mathrm{~cm}$ (width). The chambers were located in separate compartments of a wooden cabinet whose floor, walls and ceiling were painted white. The sidewalls and ceiling of the chambers were made of aluminum and the back and front walls were made of clear plastic. The floor consisted of stainless steel rods, $2 \mathrm{~mm}$ in diameter, spaced $10 \mathrm{~mm}$ apart, (center to center). A tray below the floor contained bedding material. A speaker, mounted on the back wall of each cabinet, was used for the presentation of a $30-$ sec auditory stimulus (either a $1000-\mathrm{Hz}$ tone or white noise). Each stimulus measured $75 \mathrm{~dB}$ (A scale) against a background noise of $\sim 60 \mathrm{~dB}$ measured by a digital sound level meter (Dick Smith Electronics). A constant-current shock generator, which delivered unscrambled AC $50 \mathrm{~Hz}$ to the grid floor of the conditioning chamber, was used for the presentation of a $0.35 \mathrm{~mA}, 0.5$-sec footshock.

The second set of chambers, designated $\mathrm{B}$, was located in a separate room in the laboratory. Each of the four chambers of this set measured $30 \mathrm{~cm}$ (height) $\times 27 \mathrm{~cm}$ (length) $\times 30 \mathrm{~cm}$ (width). The front and rear walls of these chambers, as well as the hinged lid, were made of clear plastic, and the side walls were made of aluminum. The floor of each chamber consisted of stainless steel rods, $5 \mathrm{~mm}$ in diameter, spaced $10 \mathrm{~mm}$ apart, (center to center), with a tray below containing bedding material. Each chamber was located in separate compartments of a wooden cabinet which was identical to that described above. The speaker that delivered the auditory stimuli was located on the side wall of the cabinets. Each stimulus measured $75 \mathrm{~dB}$ against a background noise of $60 \mathrm{~dB}$. Pumps delivered an $8 \%$ sucrose solution into a recessed magazine on the right wall of the chamber. The pumps were located above each chamber and connected to spouts at the rear of the magazine via polyethylene tubing.

In both sets of chambers, a camera mounted on the back wall of each cabinet recorded the behavior of each rat. The camera was connected to a monitor and DVD recorder in another room of the 
laboratory. An infrared light source illuminated each chamber $(940 \pm 25 \mathrm{~nm})$. All stimulus presentations were controlled by appropriate software (MatLab, MathWorks).

Experiments 3 and 4 were conducted in a single set of four conditioning chambers. Each of the chambers measured $30 \mathrm{~cm}$ (height) $\times 27 \mathrm{~cm}$ (length) $\times 30 \mathrm{~cm}$ (width). The chambers were located in separate compartments of a wooden cabinet whose floor, walls and ceiling were painted black. The sidewalls and ceiling of the chambers were made of aluminum and the back and front walls were made of clear plastic. The front wall was hinged to permit placement of the rat in the chamber. A tray below the floor contained bedding material. A speaker, mounted on the back wall of each cabinet, was used for the presentation of a 30-sec auditory stimulus (either a $1000-\mathrm{Hz}$ tone or white noise). Each stimulus measured $75 \mathrm{~dB}$ (A scale) against a background noise of $\sim 60 \mathrm{~dB}$ measured by a digital sound level meter (Dick Smith Electronics). The visual stimuli consisted in steady illumination of key lights located on either side of a recessed magazine that was positioned in the middle of the right end wall, and a flashing house light located on the end wall opposite the magazine. A constant-current shock generator, which delivered unscrambled AC $50 \mathrm{~Hz}$ to the grid floor of the conditioning chamber, was used for the presentation of a $0.35 \mathrm{~mA}, 0.5 \mathrm{sec}$ footshock. Pumps delivered an $8 \%$ sucrose solution into the magazine. The pumps were located above each chamber and connected to spouts at the rear of the magazine via polyethylene tubing.

This single set of chambers was manipulated to yield the three experimental contexts, A, B, and C. In A, the floor consisted of stainless steel rods, $5 \mathrm{~mm}$ in diameter, spaced $10 \mathrm{~mm}$ apart, (center to center). In B and C, a Perspex sheet was inserted to cover the stainless steel rods: this sheet was plain in one case and covered in sandpaper in the other. The physical identity of the modification used to generate contexts B and C, the auditory stimulus designated CS1 or CS2, and the visual stimulus designated CS3 or CS4, was fully counterbalanced.

In each chamber, a camera mounted on the back wall of each cabinet recorded the behavior of each rat. The camera was connected to a monitor and DVD recorder in another room of the laboratory. An infrared light source illuminated each chamber $(940 \pm 25 \mathrm{~nm})$. All stimulus presentations were controlled by appropriate software (MedPC, MedAssociates).

\section{Procedure}

\section{Experiment 1}

On each of days 1 and 2, rats were exposed to contexts $A$ and $B$. Half the rats in each group were exposed to these contexts in the order $\mathrm{ABBA}$, while remaining rats were exposed in the order BAAB. Each exposure lasted $20 \mathrm{~min}$, and the interval between exposures on the same day was at least $90 \mathrm{~min}$. In A, rats were not exposed to any scheduled events. In B, rats received $20 \times 0.1 \mathrm{~mL}$ presentations of an $8 \%$ sucrose solution. These presentations were unsignaled and occurred according to a variable time 60 -sec schedule. They were intended to encourage rats to approach and drink sucrose from the magazine. On day 3, rats received four tone-shock pairings in A. The intertrial interval was fixed at $3 \mathrm{~min}$. The CS was presented for $30 \mathrm{sec}$ and the US was delivered once, $5,10,20$, or $25 \mathrm{sec}$ after CS onset. Each of these CS onset-shock intervals occurred across the four trials. The order in which they occurred was randomized across rats. Each rat remained in the context for 2 min after the final pairing.

On each of days $4-6$, rats received a single session of training in B. For rats in Group Counterconditioning (CC), this training consisted of eight tone-sucrose pairings. The interval between the pairings was $180 \mathrm{sec}$. On each trial, sucrose was delivered once at a random time during the 30-sec CS presentation. For rats in Group Extinction (EXT), the training across days $4-6$ consisted in a single daily session in which there were eight 30 -sec tone presentations with a 180 -sec intertrial interval (CS onset to CS onset). There were no other scheduled events during these sessions. On day 7, rats were tested with the tone in A. Tone presentations began 2 min after placement in the context.
There were eight 30-sec tone presentations with a fixed intertrial interval of $120 \mathrm{sec}$. There were no other scheduled events in this session.

\section{Experiment 2}

On each of days 1 and 2 , rats received twice daily exposures to each of the experimental contexts, A and B, in the manner described previously. On day 3, rats received four CS1-shock and four CS2-shock pairings. The tone and white noise (described previously) were counterbalanced across the stimulus identities, CS1 and CS2. Half the rats were exposed to the trial sequence CS1CS2-CS2-CS1 $(\times 2)$, while remaining rats were exposed to the reverse sequence CS2-CS1-CS1-CS2 $(\times 2)$. The first trial occurred after $2 \mathrm{~min}$ and the interval between subsequent trials was fixed at $3 \mathrm{~min}$. The CS duration was $30 \mathrm{sec}$ and shock $(0.35 \mathrm{~mA} \times 0.5$ sec) was delivered once during each CS presentation in the manner described previously. The rats remained in the context for 2 min after the final CS presentation.

On each of days 4-6, rats received a single session of training in context B, during which they were exposed to eight presentations of CS1 and eight presentations of CS2. Half the rats were exposed to the trial sequence CS1-CS2-CS2-CS1 $(\times 4)$ while remaining rats were exposed to the reverse sequence CS2-CS1CS1-CS2 $(\times 4)$. The first trial occurred after $2 \mathrm{~min}$ and the interval between each CS presentation (offset to onset) was $150 \mathrm{sec}$. Each CS presentation lasted $30 \mathrm{sec}$. During each presentation of CS1, $0.1 \mathrm{~mL}$ of sucrose was delivered once in the manner described in Experiment 1A. During each presentation of CS2, no events were scheduled to occur. On day 7, rats were returned to context $\mathrm{A}$ and tested with CS1 and CS2. After 2 min of context alone exposure, rats were exposed to eight CS1 alone presentations and eight CS2 alone presentations. Half the rats were exposed to the trial sequence CS1-CS2-CS2-CS1 $(\times 4)$ while remaining rats were exposed to the reverse sequence CS2-CS1-CS1-CS2 $(\times 4)$. Each CS presentation lasted $30 \mathrm{sec}$ and the interval between presentations was fixed at $180 \mathrm{sec}$.

\section{Experiment 3}

On each of days 1 and 2 , rats received twice daily 20 min exposures to contexts $\mathrm{A}, \mathrm{B}$, and $\mathrm{C}$. The physical identity of the context designated B or C was fully counterbalanced. In each of the sessions in contexts $\mathrm{B}$ and $\mathrm{C}$, rats were exposed to 20 unsignaled presentations of a $0.1 \mathrm{~mL}$ sucrose solution (8\%) according to a variable time 60 -sec schedule. On day 3, rats received fear conditioning to four CSs in context A. There were four pairings of each CS, CS1, CS2, CS3, and CS4, and footshock. These 16 trials occurred in a pseudorandom order with the constraint that no more than two pairings of a given CS and footshock could occur in succession. The first trial occurred 2 min after placement in the context and the interval between subsequent trials was fixed at $3 \mathrm{~min}$. On each trial, the CS was presented for $30 \mathrm{sec}$ and the $0.35 \mathrm{~mA}, 0.5$-sec US was delivered once during the CS according to the variable time $30-\mathrm{sec}$ schedule described previously. Each rat remained in the context for 2 min after the final conditioning trial.

On each of days $4-7$, rats received alternating exposures to contexts B and $\mathrm{C}$. In context $\mathrm{B}$, rats were exposed to eight presentations of CS1 and eight of CS2. Half the rats were exposed to the trial sequence CS1-CS2-CS2-CS1 $(\times 4)$ while remaining rats were exposed to the reverse sequence CS2-CS1-CS1-CS2 $(\times 4)$. In context C, rats were exposed to eight presentations of CS3 and eight of CS4. Half the rats were exposed to the trial sequence CS3-CS4-CS4-CS3 $(\times 4)$ while remaining rats were exposed to the reverse sequence CS4-CS3-CS3-CS4 $(\times 4)$. In each session, the first trial occurred after 2 min and the interval between each CS presentation (offset to onset) was $150 \mathrm{sec}$. Each CS presentation lasted 30 sec. During each presentation of CS1 in B and of CS3 in $\mathrm{C}$, sucrose $(0.1 \mathrm{~mL})$ was delivered once on the variable time 30 -sec schedule described previously. During each presentation of CS2 in $\mathrm{B}$ and CS4 in C, no events were scheduled to occur. 
On days 8 and 9 , rats were tested with CS1 and CS2 in contexts $\mathrm{B}$ and context $\mathrm{C}$ under conditions of extinction. The order in which rats were tested in context $B$ and context $C$ was counterbalanced. Each session commenced with a 2 -min stimulus free period. Rats then received eight presentations of CS1 and eight of CS2. Half the rats were exposed to the trial sequence CS1-CS2CS2-CS1 $(\times 4)$ while the remaining rats were exposed to the reverse sequence CS2-CS1-CS1-CS2 $(\times 4)$. Each CS presentation lasted $30 \mathrm{sec}$ and the interval between presentations was fixed at $120 \mathrm{sec}$.

\section{Experiment 4}

The details for context preexposure, magazine training, fear conditioning, counterconditioning, and extinction were the same as those described in Experiment 3. On days 1 and 2, rats received daily exposures to contexts $\mathrm{A}, \mathrm{B}$, and $\mathrm{C}$. The physical identity of the context designated $\mathrm{B}$ or $\mathrm{C}$ was fully counterbalanced. In each of the sessions in contexts $\mathrm{B}$ and $\mathrm{C}$, rats were exposed to 20 unsignaled presentations of a $0.1 \mathrm{~mL}$ sucrose solution (8\%) according to a variable time 60 -sec schedule. On day 3 , rats received fear conditioning to four CSs, CS1, CS2, CS3, and CS4, in context A. The physical identity of the auditory stimulus designated CS1 or CS2, and the visual stimulus designated CS3 or CS4, was fully counterbalanced. On each of days $4-7$, rats received alternating exposures to contexts $\mathrm{B}$ and $\mathrm{C}$. In context $\mathrm{B}$, rats were exposed to eight presentations of CS1 and eight of CS2; in context C, they were exposed to eight presentations of CS3 and eight of CS4. The timing, duration, and order of stimulus presentations were the same as those used in Experiment 3. During each presentation of CS1 in B and of CS3 in C, sucrose $(0.1 \mathrm{~mL})$ was delivered once on the variable time 30 -sec schedule described previously. During each presentation of CS2 in B and CS4 in C, no events were scheduled to occur.

On days 8 and 9 rats were tested with two compounds, one composed of CS1 and CS4 and the other containing CS2 and CS3, in contexts B and C under conditions of extinction. The order in which rats were tested in context $B$ and context $C$ was counterbalanced. Each test session commenced with a 2-min stimulus free period. Rats then received eight presentations of CS1CS4 and eight of CS2CS3. Half the rats were exposed to the trial sequence CS1CS4-CS2CS3-CS2CS3-CS1CS4 $(\times 4)$ while the remaining rats were exposed to the reverse sequence CS2CS3-CS1CS4CS1CS4-CS2CS3 $(\times 4)$. Each compound presentation lasted $30 \mathrm{sec}$ and the interval between presentations was fixed at $120 \mathrm{sec}$.

\section{Scoring and statistics}

Each session of stage 2 (counterconditioning and extinction) and the test session were recorded to DVD and the behavior of each rat was scored using a time-sampling procedure. Each rat was observed every 2 sec during pre-CS and CS periods and scored as either freezing or not freezing where freezing was the absence of all movements apart from those required for breathing (Fanselow 1980). During Stage 2, each rat was also scored every 2 sec during pre-CS and CS periods for magazine entries, specifically, whether its head was in or out of the magazine. Freezing and magazine entries were scored independently. Therefore, if a rat was freezing with its head in the magazine both behaviors were scored, though samples in which this occurred were rare. In general, rats that were freezing were not in the magazine and vice versa. An observer, naïve to the purposes of each experiment, also scored all test data and a proportion of the data from training in stage 2 . Separate measures of interrater reliability were obtained for freezing and magazine entry data by correlating the two sets of scores (experimenter's and naïve observer's) for training in stage 2 and testing in stage 3. Interrater reliability for freezing and magazine entry data was high across all experiments, $r>0.90$. Freezing and magazine entries were analyzed separately. These data were analyzed with a contrast testing procedure with $\alpha=0.05$ (Hays 1963). Confidence intervals (95\% for the mean difference, standardized using the sample standard deviation) and effect size (Cohen's $d$ ) are reported for each significant comparison.
N.B. In Experiment 1, a recording failure resulted in the loss of data for eight rats across stage 2 training in context B. Therefore, the degrees of freedom for analyses of the remaining data from this stage of training were 1 and 6 , yielding an $F$ critical of 5.99 .

\section{Acknowledgments}

The authors thank anonymous reviewers for their suggested improvements to the manuscript.

\section{Competing interest statement}

The authors declare no competing financial interests.

\section{References}

Bouton ME. 1991. A contextual analysis of fear extinction. In Handbook of behavior therapy and psychological science: an integrative approach (ed. Martin PR), pp. 435-453. Pergamon Press, New York.

Bouton ME. 1993. Context, time, and memory retrieval in the interference paradigms of Pavlovian learning. Psychol Bull 114: 80-99.

Bouton ME. 1994. Context, ambiguity and classical conditioning. Curr Dir Psychol Sci 3: 49-53.

Bouton ME. 2002. Context, ambiguity, and unlearning: sources of relapse after behavioral extinction. Biol Psychiatry 52: 976-986.

Bouton ME. 2004. Context and behavioral processes in extinction. Learn Mem 11: $485-494$.

Bouton ME, Peck AP. 1992. Spontaneous recovery in cross-motivational transfer (counter-conditioning). Anim Learn Behav 20: 313-321.

Brooks DC, Hale B, Nelson JB, Bouton ME. 1995. Reinstatement after counter-conditioning. Anim Learn Behav 23: 383-390.

Capaldi ED, Viveiros DM, Campbell DH. 1983. Food as a contextual cue in counterconditioning experiments: is there a counterconditioning process? Anim Learn Behav 11: 213-222.

Delamater AR. 2004. Experimental extinction in Pavlovian conditioning: behavioural and neuroscience perspectives. Q J Exp Psychol B 57: 97-132.

Delamater AR, Westbrook RF. 2014. Psychological and neural mechanisms of experimental extinction: a selective review. Neurobiol Learn Mem 108: $38-51$.

Dickinson A, Pearce JM. 1977. Inhibitory interactions between appetitive and aversive stimuli. Psychol Bull 84(4): 690-711.

Dunsmoor JE, Campese VD, Ceceli AO, LeDoux JE, Phelps EA. 2015. Novelty-facilitated extinction: providing a novel outcome in place of an expected threat diminishes recovery of defensive responses. Biol Psychiatry 78: 203-209.

Fanselow MS. 1980. Conditioned and unconditional components of post-shock freezing. Pavlov J Biol Sci 15: 177-182.

Harris JA, Jones ML, Bailey GK, Westbrook RF. 2000. Contextual control over conditioned responding in an extinction paradigm. J Exp Psychol Anim Behav Process 26: 174-185.

Hays WL. 1963. Statistics for psychologists. Holt, Rinehart and Winston, New York.

Holmes NM, Westbrook RF. 2013. Extinction of reinstated or ABC renewed fear responses renders them resistant to subsequent ABA renewal. J Exp Psychol Anim Behav Process 39: 208-220.

Holmes NM, Cai SY, Lay BPP, Watts NR, Westbrook RF. 2014. Extinguished second-order conditioned fear responses are renewed but not reinstated. J Exp Psychol Anim Learn Cogn 40: 440-456.

Larrauri JA, Schmajuk NA. 2008. Attentional, associative, and configural mechanisms in extinction. Psychol Rev 115: 640-676.

Leung HT, Reeks L, Westbrook RF. 2012. Two ways to deepen extinction and the difference between them. J Exp Psychol Anim Behav Process 38: 394-406.

Loftus GR, Masson MEJ. 1994. Using confidence intervals in within-subject designs. Psychon Bull Rev 1: 476-490.

Lovibond PF, Davis NR, O'Flaherty AS. 2000. Protection from extinction in human fear conditioning. Behav Res Ther 38: 967-983.

Lovibond PF, Mitchell CJ, Minard E, Brady A, Menzies RG. 2009. Safety behaviours preserve threat beliefs: protection from extinction of human fear conditioning by an avoidance response. Behav Res Ther 47: $716-720$.

Peck AP, Bouton ME. 1990. Context and performance in aversive-to-appetitive and appetitive-to-aversive transfer. Learn Motiv 21: $1-31$.

Redish AD, Jensen S, Johnson A, Kurth-Nelson Z. 2007. Reconciling reinforcement learning models with behavioral extinction and 
renewal: implications for addiction, relapse, and problem gambling. Psychol Rev 114: 784-805.

Rescorla RA. 2006. Deepened extinction from compound stimulus presentation. J Exp Psychol Anim Behav Process 32: 135-144.

Rescorla RA. 2008. Within-subject renewal in sign tracking. Q J Exp Psychol (Hove) 61: 1793-1802.

Rescorla RA, Wagner AR. 1972. A theory of Pavlovian conditioning: variations in the effectiveness of reinforcement and nonreinforcement.
In Classical conditioning II: current research and theory (ed. Black AH, Prokasy WF). Appleton-Century-Crofts, New York.

Van Gucht D, Baeyens F, Hermans D, Beckers T. 2013. The inertia of conditioned craving. Does context modulate the effect of counterconditioning? Appetite 65: 51-57.

Received October 11, 2015; accepted in revised form January 22, 2016. 


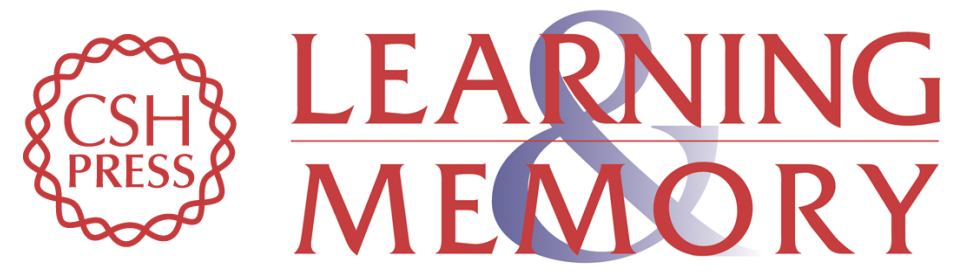

\section{Counterconditioned fear responses exhibit greater renewal than extinguished fear responses}

Nathan M. Holmes, Hiu T. Leung and R. Frederick Westbrook

Learn. Mem. 2016, 23:

Access the most recent version at doi:10.1101/Im.040659.115

References This article cites 25 articles, 1 of which can be accessed free at:

http://learnmem.cshlp.org/content/23/4/141.full.html\#ref-list-1

Creative This article is distributed exclusively by Cold Spring Harbor Laboratory Press for the

Commons

first 12 months after the full-issue publication date (see

License http://learnmem.cshlp.org/site/misc/terms.xhtml). After 12 months, it is available under a Creative Commons License (Attribution-NonCommercial 4.0 International), as described at http://creativecommons.org/licenses/by-nc/4.0/.

Email Alerting Receive free email alerts when new articles cite this article - sign up in the box at the Service top right corner of the article or click here. 